\title{
Observation of Phenyl-Fused Porphyrinoids During the ESI Mass Spectrometric Analysis of meso-Pentafluorophenyl-Substituted Porphyrin and Corrole
}

\author{
Kimberly S. F. Lau, Martin Sadilek, Martin Gouterman, \\ and Gamal E. Khalil \\ Department of Chemistry, University of Washington, Seattle, Washington, USA \\ Christian Brückner \\ Department of Chemistry, University of Connecticut, Storrs, Connecticut, USA
}

\begin{abstract}
The results of ESI(+) and ESI(-) mass spectrometry/mass spectrometry investigations of meso-tetrakisphenylporphyrin (TPP) and meso-trisphenylcorrole (TPC) in comparison with their meso-tetrakis(pentafluorophenyl)-substituted analogs $\mathrm{T}^{\mathrm{F}} \mathrm{PP}$ and $\mathrm{T}^{\mathrm{F}} \mathrm{PC}$ are reported. The fragmentation patterns of TPP and TPC show the expected loss of meso-aryl radicals. Analyzing the meso-pentafluorophenyl substituted analogs $\mathrm{T}^{\mathrm{F}} \mathrm{PP}$ and $\mathrm{T}^{\mathrm{F}} \mathbf{P C}$, we found $\mathrm{ESI}(-)$ to be an excellent ionization mode. Rich and well-defined HF-elimination fragmentation patterns unique to the presence of meso-tetrafluorophenyl groups and evocative for the formation of fragments with direct covalent $o$-phenyl-to- $\beta$-linkages are observed. A computation of the feasibility and relative energies of the resulting species corroborates the interpretation of the experimental findings. The computations indicate the presence of cooperative interactions between the linkages that direct the linkage formations to occur in a unidirectional fashion. MS/MS/MS experiments also provide indications for the regioselectivity of the fusions. Our observations further detail earlier reports of similar HF-eliminations and allow a generalization of the findings. The results presented may also point to strategies towards the bulk synthesis of novel porphyrinoid structures. (J Am Soc Mass Spectrom 2006, 17, 1306-1314) (c) 2006 American Society for Mass Spectrometry
\end{abstract}

$m$ eso-tetraarylporphyrins, the parent compound of which is meso-tetrakisphenylporphyrin (TPP), are the most widely studied class of synthetic porphyrins (Figure 1). Their popularity as, for instance, model compounds for naturally occurring cofactors arises from their straightforward syntheses and the option to widely vary the type of substituents on the aryl rings [1]. One particular mesoaryl group, the electron-withdrawing pentafluorophenyl group, is commonly utilized when chemical inertness is to be imparted onto the porphyrinic macrocycle, such as increased stability toward oxidative degradation [2-6]. Metalloporphyrins and metallocorroles (based on the ligand meso-tris(pentafluorophenyl)corrole, $\mathrm{T}^{\mathrm{F}} \mathbf{P C}$ ) used in group transfer catalyses also take advantage of the stabilizing effects of the pentafluorophenyl moiety [5-7]. The meso-pentafluorophenyl group was introduced into porphyrin isomers ( $\mathrm{N}$-con-

Published online July 18, 2006

Address reprint requests to Dr. C. Brückner, Department of Chemistry, University of Connecticut, Unit 3060, Storrs, CT 06269-3060, USA. E-mail: c.bruckner@uconn.edu fused porphyrins) [8, 9], as well as into expanded porphyrins [10].

meso-Tetraarylporphyrins are generally potent singlet oxygen photosensitizers that have been utilized in the photodynamic destruction of neovascular tissue [11]. The quenching of the photo-excited triplet state of $\mathrm{Pt}$ (II) complexes of porphyrins is the origin of their utility in pressure-sensitive paints (PSP) that allow for the continuous mapping of surface pressures [12-16]. We have found that the use of the fluorinated ligand $\mathrm{T}^{\mathrm{F}} \mathbf{P P}$ in PSP formulations increases the phosphorescence lifetime of the paints and leads to photo-stable coatings, presumably because of the protection the pentafluorophenyl groups provide from singletoxygen-mediated oxidative degradation of the chromophore [13-16]. Further, $\mathbf{T}^{\mathrm{F}} \mathbf{P P}$ was suggested as a chemically inert and strongly light-absorbing matrix in MALDI-TOF mass spectrometry [17].

While the protection from undesired reactions on the porphyrinic macrocycle is the impetus for the use of the pentafluorophenyl group in the above examples, the $p$-position of the pentafluorophenyl group is activated toward a nucleophilic aromatic substitution reaction. 

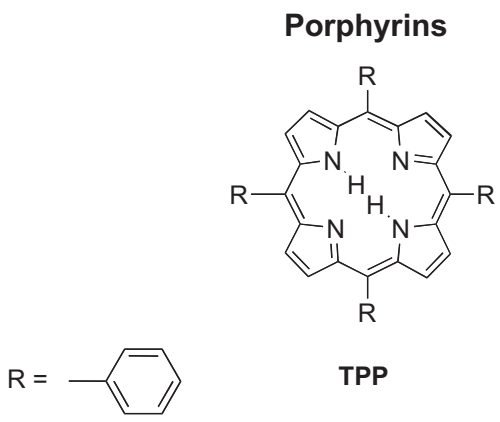

TPP

$\mathrm{T}^{\mathrm{F} P \mathrm{P}}$

TFP

Figure 1. Structure and naming convention of the macrocycles investigated

Commonly using $N$ - or $S$-nucleophiles, the pentafluorophenyl group can therefore be used to regiospecifically introduce p-phenyl substituents [18-21]. Further, the pentafluorophenyl groups mediate the solubility of porphyrins in fluorinated solvents and supercritical $\mathrm{CO}_{2}[22,23]$. Lastly, ${ }^{19} \mathrm{~F}$ is NMR active, and the pentafluorophenyl group offers a convenient NMR tag to elucidate the structure of complex porphyrinic derivatives $[3,24]$.

The many uses for meso-pentafluorophenyl groups make efficient analysis of these compounds desirable. Electrospray ionization (ESI) mass spectrometry (MS) is becoming a popular technique for the analyses of porphyrins [25-35].

During the mass spectrometric analysis of variously $\beta$-substituted meso-phenylporphyrins, ring-closure reactions involving the meso-phenyl group have been observed before. For instance, $\beta$-nitro- and $\beta$-vinylsubstituted porphyrins form, under FAB conditions, fragment ions enclosing six-membered rings, such as structures 1 and 2, respectively (Figure 2) [30]. Inversely, $p$-nitrophenyl-substituted porphyrins do not undergo this type of cyclization. Hence, this reaction can be utilized for the determination of these regioisomers of nitroporphyrins by mass spectrometry/mass spectrometry (MS/MS) [36].

We report here on the results of ESI MS and MS/MS investigations of a meso-pentafluorophenyl-substituted porphyrin $\left(\mathrm{T}^{\mathrm{F}} \mathbf{P P}\right)$ and -corrole $\left(\mathrm{T}^{\mathrm{F}} \mathbf{P C}\right)$ in comparison with their nonfluorinated analogs TPP and TPC. Welldefined fragmentation patterns characteristic for the presence of meso-tetrafluorophenyl groups that are evocative of the formation of fragments with covalent $o$-phenyl-to- $\beta$-linkages are observed. Equivalent HFelimination-mediated $o$-to- $\beta$-linkage formations enclosing a five-membered ring between the meso-aryl group and the porphyrin ring, were recently reported by Izquerido et al. [33]. They reported the occurrence of these linkages of type 3 in the collision-induced dissociation ESI-MS spectra of meso-pentafluorophenyl derivat- ized cationic pyrrolidine-fused chlorins and isobacteriochlorins [33]. A host of fragmentations characteristic for pyrrolidine-fused systems were found among a limited number of these HF-loss mediated cyclization reactions. We demonstrate here that formation of $\beta$-to-o-linkages during the MS/MS analysis of meso-tetrafluorophenylporphyrins follows predictable and rational patterns. In certain cases, all theoretically conceivable ring-closures can be observed, and the reaction appears to be general for meso-pentafluorophenyl-substituted porphyrinoids.

\section{Experimental}

TPP [37] and TPC [38] were synthesized according to literature methods. $\mathbf{T}^{\mathrm{F}} \mathbf{P P}$ was purchased from Frontier Science, Inc. (Logan, UT).

The computations were performed using CambridgeSoft Chem3D Pro Version 5, 1999 (Cambridge, MA), MM2 basis set and were run to convergence (minimum RMS gradient 0.1).

All mass spectrometry data were obtained using an ion trap mass spectrometer EsquireLC (Bruker Daltonics, Billerica, MA) with electrospray ionization source. Samples were dissolved in spectral grade $\mathrm{CH}_{2} \mathrm{Cl}_{2}$ and diluted in $\mathrm{CH}_{3} \mathrm{CN}$ to approximate $\mu \mathrm{M}$ concentrations. These solutions were directly infused into the ion source at a flow rate of $1 \mu \mathrm{L} / \mathrm{min}$. Spectra were collected in both positive and negative ionization mode using identical solutions. The standard tune parameters were similar for both modes: Capillary voltage 3500 to $4000 \mathrm{~V}, \Delta$ endplate $500 \mathrm{~V}$, capillary offset $70 \mathrm{~V}$, skimmer 1 set to $30 \mathrm{~V}$, skimmer 2 set to $4 \mathrm{~V}$, octupole $3 \mathrm{~V}$ and octupole $\Delta 2 \mathrm{~V}$, trap drive 55 to $75 \mathrm{~V}$, ion charge control (ICC) on and target 25,000 (10,000 in negative mode for better isotope resolution), nebulizer gas $\left(\mathrm{N}_{2}\right) 12$ psi, drying gas $\left(\mathrm{N}_{2}\right) 5 \mathrm{l} / \mathrm{min}$, drying temperature $250{ }^{\circ} \mathrm{C}$. The fragmentation spectra of the analytes were collected with an isolation width of $4 \mathrm{Da}$, fragmentation amplitude set to $1 \mathrm{~V}$, and SmartFrag On (amplitude automatically varies 30 to $200 \%$ of the set fragmentation amplitude of $1 \mathrm{~V})$.

\section{Results and Discussion}

\section{ESI(+) MS and MS/MS of TPP and TPC}

The ESI MS of TPP $\left(\mathrm{C}_{44} \mathrm{H}_{30} \mathrm{~N}_{4}\right)$, recorded in the positive ion mode, is shown in Figure 3a. The sole species formed is the expected monoprotonated parent com-
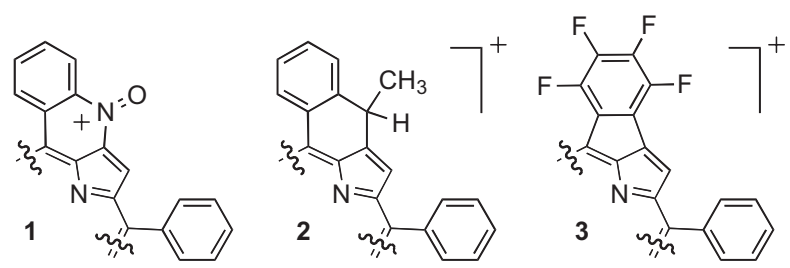

Figure 2. meso-Phenyl-fused structures previously observed during the mass spectrometric analysis of porphyrins 

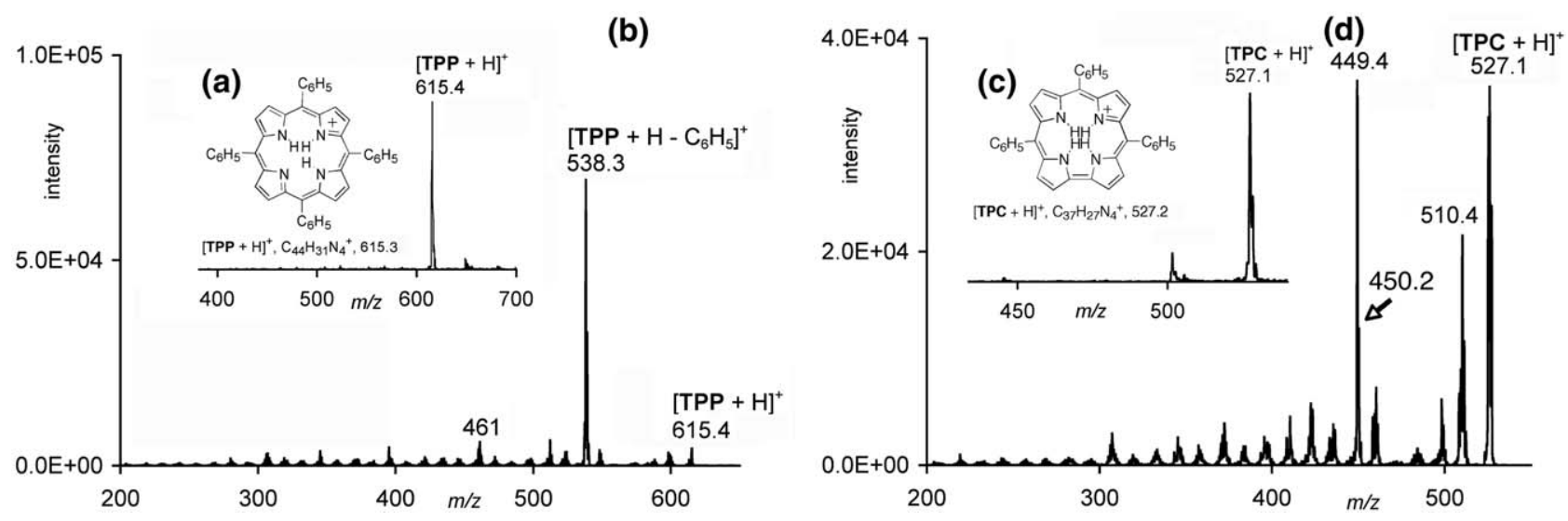

Figure 3. ESI $(+)$ mass spectra of TPP and TPC. (a) (insert): ESI $(+)$ MS of TPP. (b): ESI(+) MS/MS of the species [TPP $+\mathrm{H}]^{+}(\mathrm{m} / z$ 615). (c) (insert): ESI $(+)$ MS of TPC. $(\mathbf{d})$ : ESI $(+)$ MS/MS of the species $[\mathrm{TPC}+\mathrm{H}]^{+}(\mathrm{m} / z$ 527). The interpretation of the spectra is presented in Scheme $\mathbf{1}$.

pound $[\mathrm{TPP}+\mathrm{H}]^{+}$with a $\mathrm{m} / \mathrm{z}$ value of 615 . Protonation is likely taking place at one of the inner, basic imine nitrogens. The ESI-MS/MS spectrum of the species $[\mathrm{TPP}+\mathrm{H}]^{+}$is shown in Figure $3 \mathrm{~b}$. Collision-induced fragmentation of the singly protonated TPP results predominantly in the loss of one phenyl group as a $\mathrm{C}_{6} \mathrm{H}_{5}$ radical, forming the protonated triphenyl radical species 4 of $\mathrm{m} / z 538$ (Scheme 1). The loss of a second phenyl group (expected $\mathrm{m} / \mathrm{z}$ of 461.2 ) is of relatively low abundance. In general, these findings have been amply described before and serve here simply as benchmark data against which we evaluate the behavior of the pentafluorophenyl-derived analog $[25,29,32]$.

The ESI $(+)$ MS of triphenylcorrole TPC (Figure 3c) parallels that of TPP. The major species present are the respective $\mathrm{MH}^{+}$ions. Likewise, the ESI(+) MS/MS of the respective $\mathrm{MH}^{+}$species (Figures $3 \mathrm{~d}$ ) can largely be interpreted along the same lines as that for TPP (Scheme 1). The loss of one meso-substituent radical is a major fragmentation pathway that is accompanied by a minor pathway attributed to the breakup of the macrocycle. The apparent loss of either $m / z 77\left(-\mathrm{C}_{6} \mathrm{H}_{5}\right)$ or neutral loss of benzene $\left(78,-\mathrm{C}_{6} \mathrm{H}_{6}\right)$ is reproducible and may be a distinguishing feature for TPC. The remaining peaks resulting from the breakup of $\left[\right.$ TPC $\left.+\mathrm{H}^{+}\right]$are broad and point toward the successive loss of C- and $\mathrm{N}$-fragments with varying numbers of hydrogens.

We were not able to record interpretable spectra for either of these two macrocycles under ESI(-) conditions. This result is surprising for TPC as its acidity is reportedly much higher than that of porphyrins [39].

\section{ESI(+) and ESI(-) MS and MS/MS Analysis of $\mathrm{T}^{\mathrm{F}} \mathrm{PP}$}

When subjecting the fluorinated porphyrin $\mathbf{T}^{\mathrm{F}} \mathbf{P P}$ to the same ESI $(+)$ ionization conditions as its nonfluorinated counterpart TPP, we recorded spectra that were not as clean (cf. Figure 4a with Figure 3a). Presumably the electron-withdrawing meso-pentafluorophenyl substituents increase the acidity of the porphyrin and prevent efficient protonation. Hence, we tested the recording of the spectra in negative ionization mode (Figure 4c).

Essentially, only one ion at $\mathrm{m} / \mathrm{z} 973$ is detected, corresponding to the species $\left[\mathrm{T}^{\mathrm{F}} \mathbf{P P}-\mathrm{H}\right]^{-}$. Ionization is thus brought about by efficient deprotonation, presumably of one of the inner pyrrole-type nitrogens. The collision-induced fragmentation of the $\left[\mathrm{T}^{\mathrm{F}} \mathrm{PP}-\mathrm{H}^{-}\right.$ species is shown in Figure 4f. Four major and several

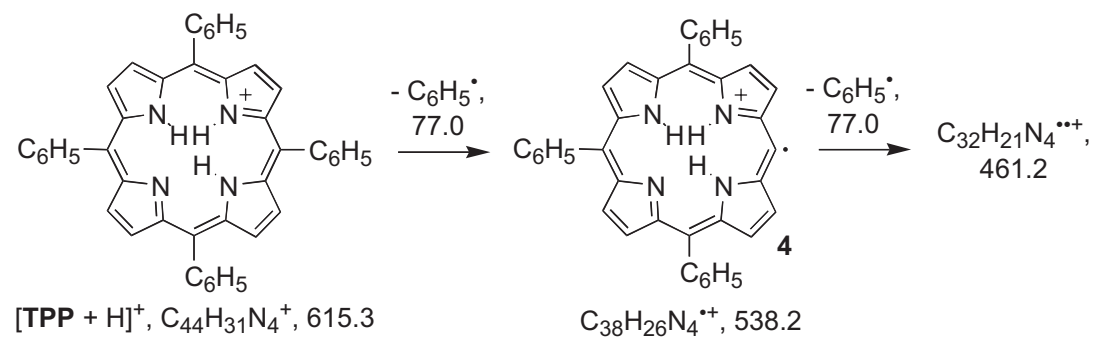

$$
\begin{array}{lll}
{\left[\mathrm{TPC}+\mathrm{H}^{+}, \mathrm{C}_{37} \mathrm{H}_{27} \mathrm{~N}_{4}{ }^{+}, 527.2 \stackrel{-\mathrm{C}_{6} \mathrm{H}_{5}, 77.0}{\stackrel{-\mathrm{C}_{6} \mathrm{H}_{6}, 78.0}{\longrightarrow}} \mathrm{C}_{31} \mathrm{H}_{22} \mathrm{~N}_{4}{ }^{-+}, 450.2\right.} \\
\mathrm{C}_{31} \mathrm{H}_{21} \mathrm{~N}_{4}{ }^{*+}, 449.2
\end{array}
$$

Scheme 1. Interpretation of the spectra shown in Figures 3a-d. 

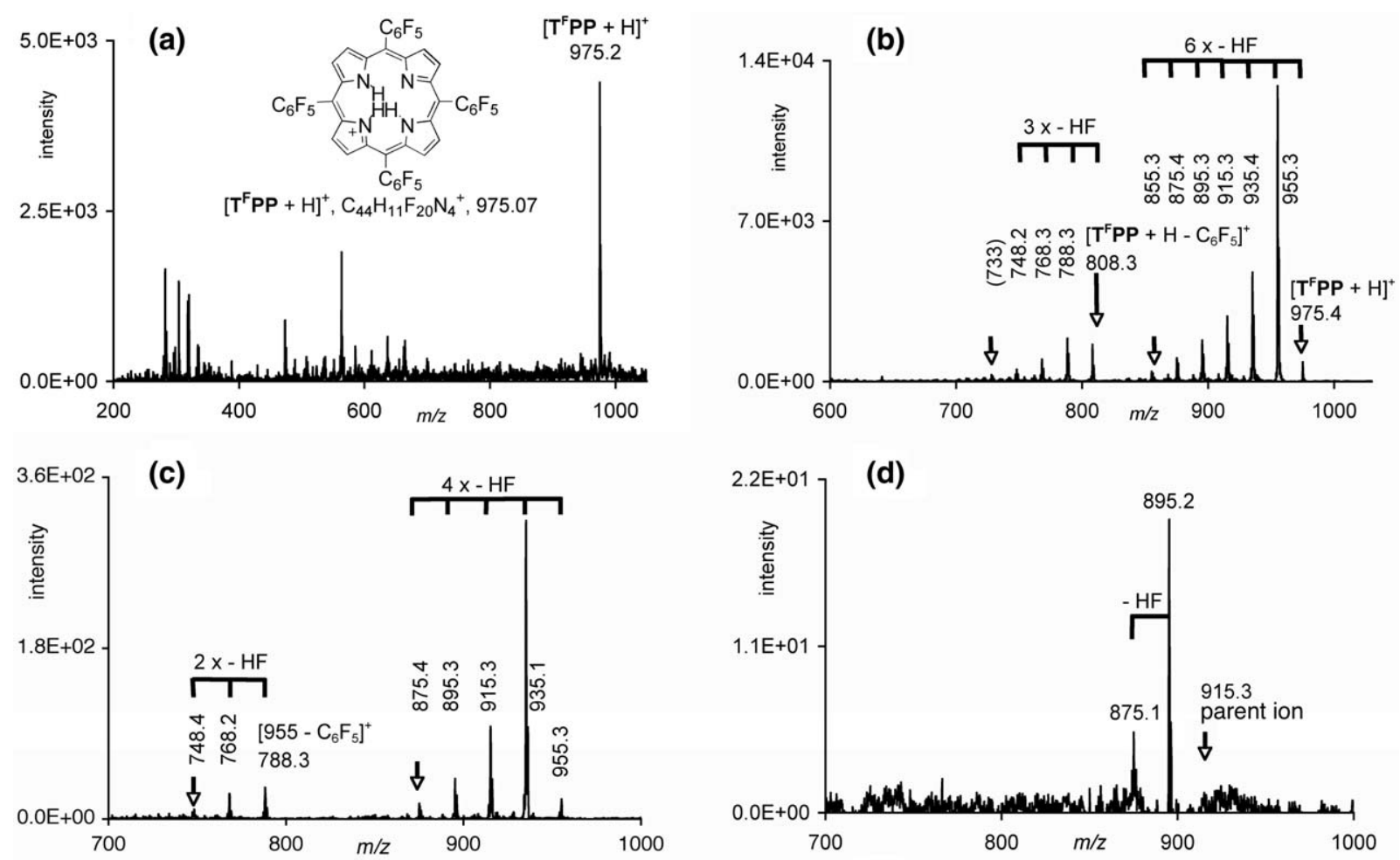

(e)
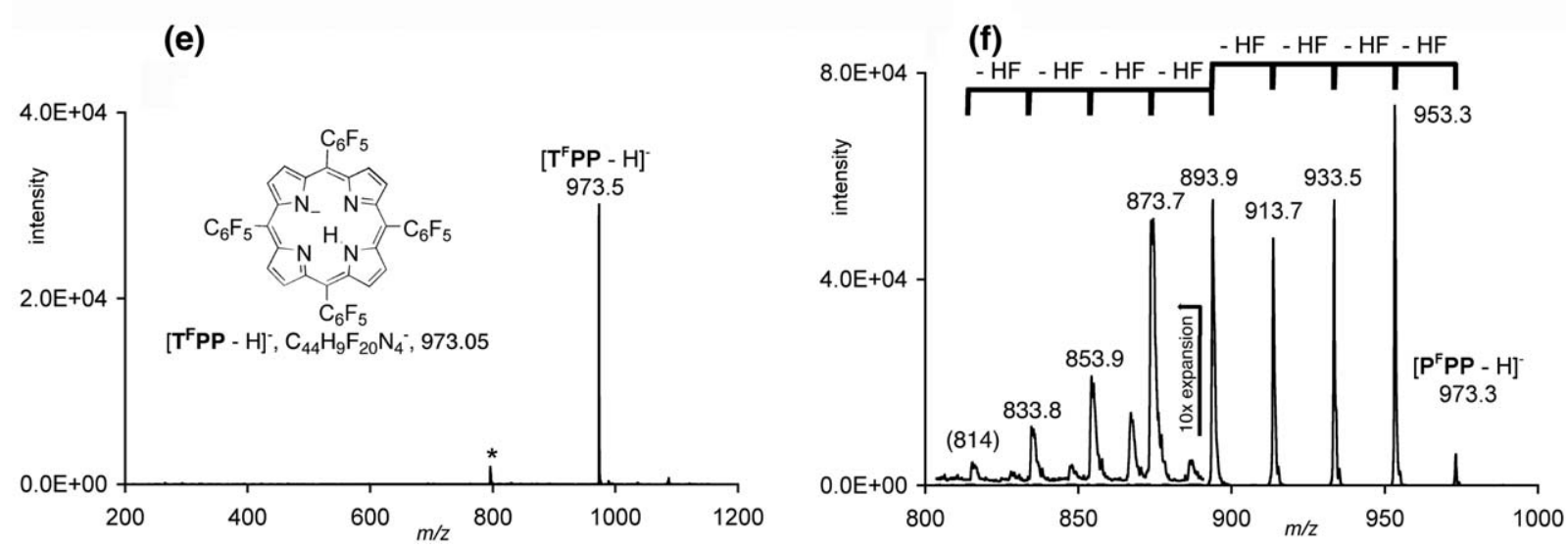

Figure 4. ESI mass spectra of $\mathbf{T}^{\mathrm{F}} \mathbf{P P}$. (a): Full scan ESI(+) MS of $\mathbf{T}^{\mathrm{F}} \mathbf{P P}$. (b): ESI(+) MS/MS of the species $\left[\mathbf{T}^{\mathbf{F}} \mathbf{P P}+\mathrm{H}\right]^{+}(\mathrm{m} / \mathrm{z}$ 975). An interpretation of the spectrum is provided in Scheme 3. (c): ESI $(+)$ MS/MS/MS spectrum of the species m/z 955 (see in Figure 4b). (d): ESI(+) MS/MS/MS spectrum of the species $m / z 915$ (see in Figure $4 \mathrm{~b}$ ). (e): Full scan ESI(-) mass spectrum. The peak marked with an asterisk (at $m / z 795$ ) is an impurity of $\mathbf{T}^{\mathrm{F}} \mathbf{P C}$ originating from the preparation of $\mathbf{T}^{\mathrm{F}} \mathbf{P P}$ (for a discussion of the origin and the MS/MS of this species, see below). (f): ESI $(-)$ MS $/ M S$ of the species $\left[T^{\mathrm{F}} \mathbf{P P}-\mathrm{H}\right]^{-}$ $(m / z$ 973). An interpretation of these spectra is shown in Scheme 2.

minor fragments are detected. Notably, the species corresponding to the loss of a pentafluorophenyl group (expected at $m / z$ 806) is absent. As the predominant fragmentation pattern, a successive loss of HF (20 Da) is observed whereby four high abundance fragments are followed by four low abundance fragments. Since a cis-elimination of HF cannot take place in $\mathbf{T}^{\mathrm{F}} \mathbf{P P}$, we surmise that the elimination is, under concomitant formation of an $o$-to- $\beta$-single bond, due to the loss of one $\mathrm{H}$ from the pyrrolic $\beta$-positions and the loss of one $\mathrm{F}$ from the $o$-position of a flanking pentafluorophenyl group. This finding mirrors a report by SantanaMarques and coworkers who also observed, amidst other fragmentations, the occurrence of HF-elimination in the collision-induced ESI-MS spectra of mesopentafluorophenyl derivatized cationic pyrrolidinefused chlorins and isobacteriochlorins that were also interpreted as the formation of $\beta$-to-o-linkages [33]. In contrast, however, $\mathrm{T}^{\mathrm{F}} \mathbf{P P}$ possesses a much simpler structure that enables the HF elimination to occur as the sole fragmentation pathway. The simplicity of the precursor ion and the purported elimination products 


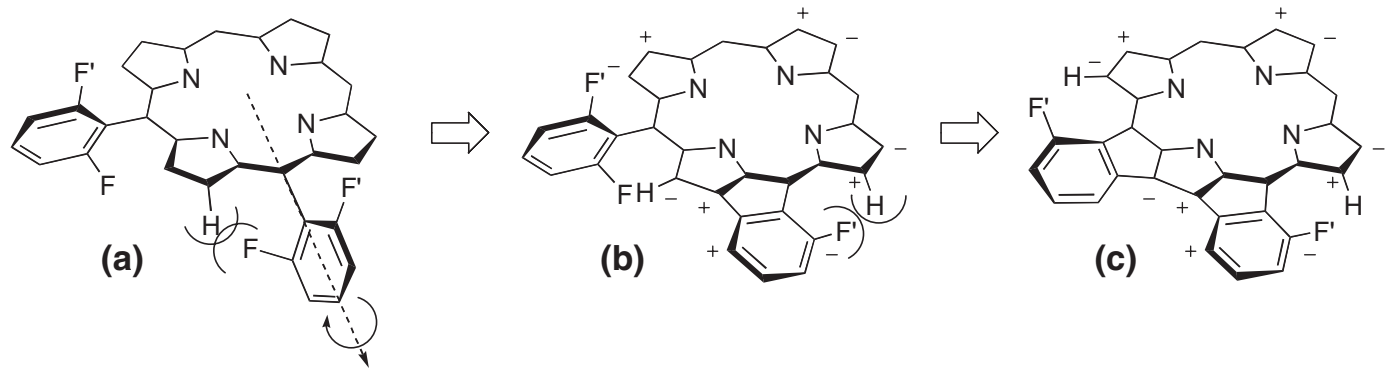

Figure 5. Illustration of the steric interaction between the $\beta$-hydrogen and the $o$-phenyl substituent in meso-phenylporphyrin (a), $o$-to- $\beta$-fused porphyrin (b), and bis-fused porphyrin (c). The plus (+) and minus ( - ) indicate the ruffled conformation of the porphyrinic macrocycle, i.e., the relative position of the atoms with respect to the mean plane of the macrocycle.

allows for a reliable molecular modeling of the process and a detailed prediction of their structures that point toward a generalization of the findings (see below).

meso-Aryl groups attached to porphyrins are, in the solution and solid-state, arranged approximately perpendicular to the mean plane of the porphyrin. This is because of a steric interaction between the $\beta$-hydrogen and the o-phenyl substituents (Structure a, Figure 5). A direct linkage between these two positions allows the phenyl group to be arranged nearly co-planar to the porphyrin but forces the opposite $o$-atom into closer proximity to the adjacent $\beta$-hydrogen. The latter interaction is perceivably alleviated by a ruffling distortion of the macrocycle (b). The resulting extension of the porphyrinic $\pi$-system, together with the liberation of $\mathrm{HF}$, are the likely driving forces for the formation of such a linkage.

The mechanism of the elimination reaction is likely that of a nucleophilic aromatic substitution $\left(\mathrm{S}_{\mathrm{NAr}}\right)$, a reaction type common for the electron-poor pentafluorophenyl group (Scheme 2) [18-21]. The elimination can be repeated four times, linking each aryl group. A

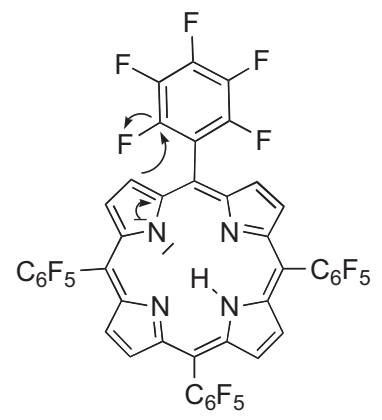

$\left[\mathrm{T}^{\mathrm{F} P P}-\mathrm{H}^{-}, \mathrm{C}_{44} \mathrm{H}_{9} \mathrm{~F}_{20} \mathrm{~N}_{4}^{-}, 973.05\right.$

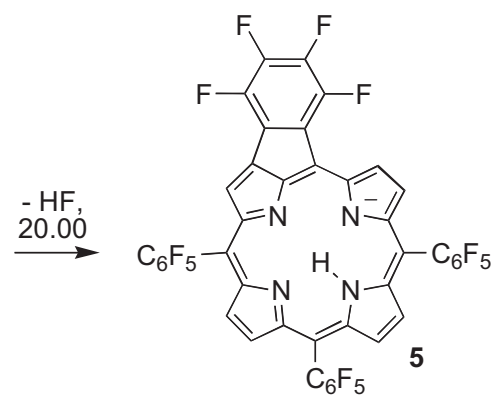

$\mathrm{C}_{44} \mathrm{H}_{8} \mathrm{~F}_{19} \mathrm{~N}_{4}^{-}, 953.05$

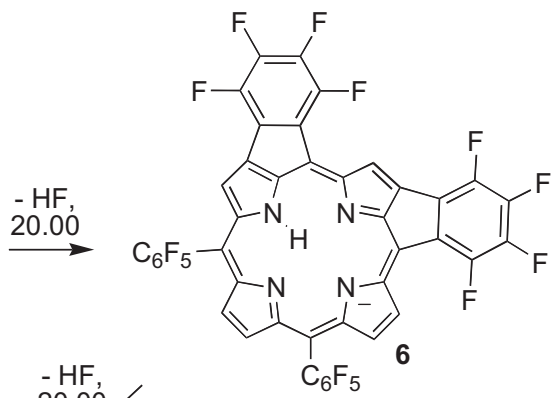

$\mathrm{C}_{44} \mathrm{H}_{7} \mathrm{~F}_{18} \mathrm{~N}_{4}^{-}, 933.04$

$\mathrm{C}_{44} \mathrm{H}_{6} \mathrm{~F}_{17} \mathrm{~N}_{4}^{-}, 913.52$

$-2 \mathrm{HF}, 40.00$

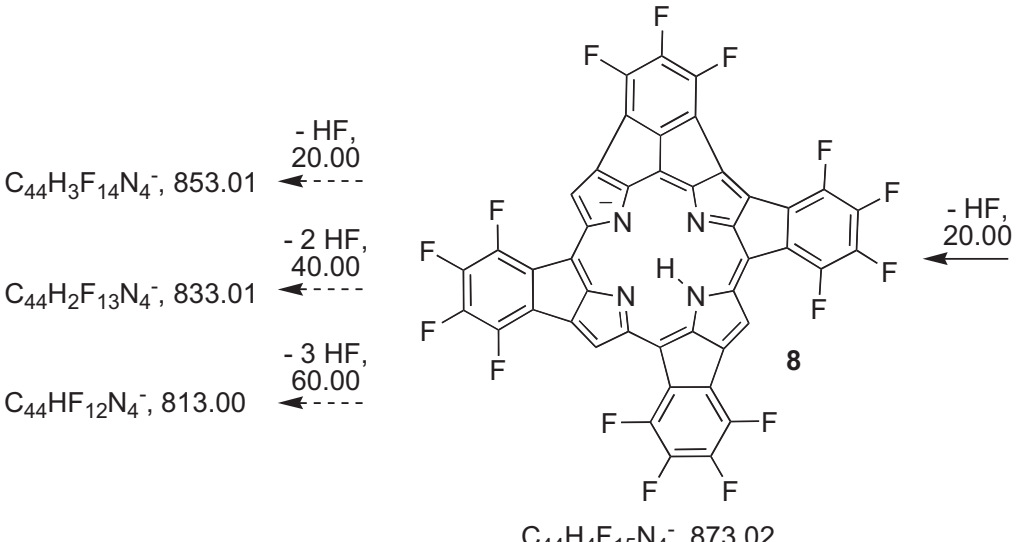

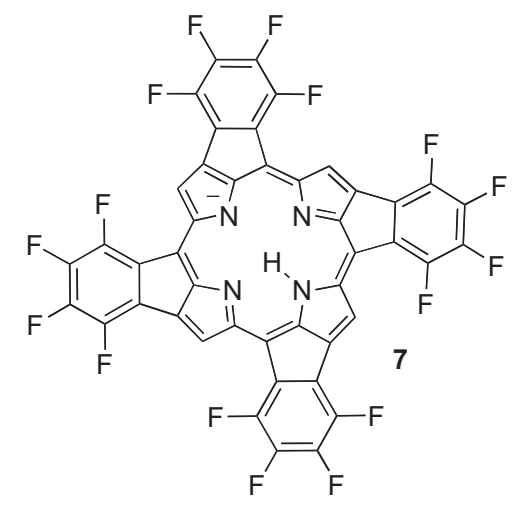

$\mathrm{C}_{44} \mathrm{H}_{5} \mathrm{~F}_{16} \mathrm{~N}_{4}^{-}, 893.03$

Scheme 2. Interpretation of the collision-induced fragmentation mass spectrum of $\left[\mathbf{T}^{\mathrm{F}} \mathbf{P P}-\mathrm{H}\right]^{-}$ (Figure 4f). 


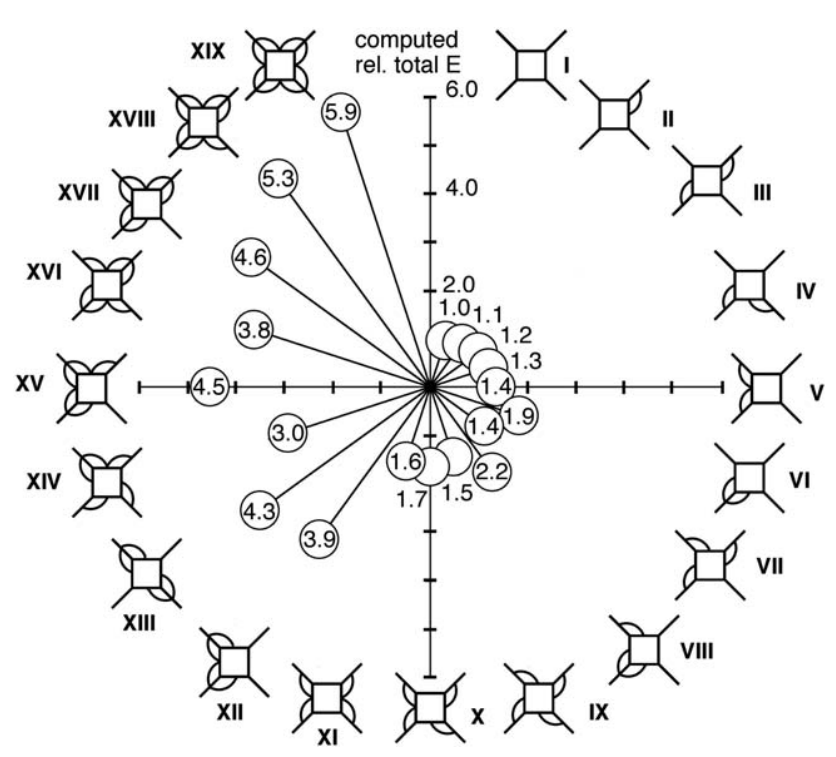

Figure 6. Computed relative (strain) energy increases upon successive formations of select $\beta$-to-o-linkages in $\mathbf{T}^{\mathrm{F}} \mathbf{P P}$. Overall energy computed for $\mathbf{I}$ is $63 \mathrm{~kJ} / \mathrm{mol}$. The compounds computed are indicated in a stylized fashion: The squares represent the porphyrin macrocycle, the straight lines the meso-phenyl groups, and the $o$-to- $\beta$-linkages are indicated by the connections between these two elements.

cooperative interaction between the linkages that orients the direction of the subsequent fusions seems plausible. If one linkage causes a ruffling distortion of the macrocycle, the ruffled conformation facilitates the formation of a second linkage in a unidirectional fashion because this does not introduce any (or only minor) additional steric interaction between the $o$-atom of the second linked aryl group and the adjacent $\beta$-hydrogen (Structure c, Figure 5). In fact, they are, as a direct result of the ruffling that translates throughout the entire macrocycle, already preoriented away from each other. Inversely, a nonunidirectional linkage goes "against the grain" and introduces additional steric interactions. Thus, the first elimination (to form 5) enables the subsequent eliminations to take place in the regioselective, unidirectional manner shown (5 to 6, 7, and finally 8 , Scheme 2). Molecular mechanics calculations corroborate this proposition.

We computed the total energy of $\mathbf{T}^{\mathrm{F}} \mathbf{P P}$ in comparison with most of the possible isomers containing one to eight $o$-to- $\beta$-linkages. The results of the computations are summarized in Figure 6 . The formation of one $\beta$-to-o-linkage (species II) increases the overall (strain) energy of the system only by $10 \%$ compared to the energy of the parent compound (I). In fact, up to four linkages increase the overall strain energy by only $50 \%$ (IX) if the linkages are connected in an unidirectional fashion. If the linkages are not established in a unidirectional fashion, as in $\mathbf{V}$ or in $\mathbf{X}$ and $\mathbf{X I}$, the energy of the system is 10 to $15 \%$ higher as compared to the unidirectional isomers IV and IX, respectively. If even one phenyl group is linked on both opositions (VI), the energy nearly doubles. Thus, all iso- mers of the species containing four linkages $(\mathbf{X}-\mathbf{X I V})$ in a nonunidirectional fashion have significantly higher energies than IX. Those bearing two doubly-linked phenyl groups possess up to threefold the energy of IX. The fifth to eighth consecutive linkages necessarily involve such doubly-linked phenyl groups and, consequently, their energies are significantly elevated. Whether these highenergy ring-fusions occur also in a unidirectional fashion could not be made out clearly.

This result correlates well with the observed relative peak intensities in the fragmentation spectrum of [ $\mathbf{T}^{\mathrm{F}} \mathbf{P P}-$ $\mathrm{H}]^{-}$(Figure 4f). The fifth and subsequent eliminations proceed with low efficiency, and the corresponding fragment peaks are minor compared to the peaks resulting from the first four eliminations (note the 10-fold intensity enhancement of the spectrum below $\mathrm{m} / \mathrm{z}$ 890). It is, therefore, not surprising that literature precedence for the bulk-phase formation of $o-, O^{\prime}$-linked phenyl groups in the solution phase are rare and involve only one phenyl group and two enclosed six-membered rings or one fiveand one six-membered ring [40, 41]. Porphyrinoids containing direct $\beta$-to-o-linkages enclosing five-membered rings between the phenyl and the porphyrin macrocycle are also known, though their establishment follow different routes than presumed here [42, 43].

In light of the foregoing, the ESI(+) MS/MS spectrum of $\left[\mathrm{T}^{\mathrm{F}} \mathbf{P P}+\mathrm{H}\right]^{+}$(Figure $4 \mathrm{~b}$ ) can qualitatively be interpreted in a similar fashion to the ESI(-) spectrum, with two notable differences (Scheme 3). First, two HF elimination series can be distinguished: one series of six eliminations beginning with the species $\left[\mathrm{T}^{\mathrm{F}} \mathbf{P P}+\mathrm{H}\right]^{+}$ (at $m / z$ 975) and ending with the fragment $9(\mathrm{~m} / z$ 855, shown is the isomer with opposite double linkages as the computations have shown this arrangement to be energetically more favorable), and one series beginning with the species $\mathbf{1 0}(\mathrm{m} / \mathrm{z}$ 808). Fragment $\mathbf{1 0}$ is derived from $\left[\mathrm{T}^{\mathrm{F}} \mathbf{P P}+\mathrm{H}\right]^{+}$by a loss of $\mathrm{C}_{6} \mathrm{~F}_{5}$ radical. Since this fragment contains fewer pentafluorophenyl groups that can lead to ring-closure, only a maximum of three HF eliminations, presumably forming species 11, are observed. A fourth elimination that requires a highly strained, doubly-fused aryl group cannot be made out clearly. Second, the mechanism is much less clear since an intramolecular nucleophilic substitution mechanism much less likely operating within a cationic pseudomolecular species, though it does not rule it out entirely. The driving force for the reaction is identical in either charge state and may drive an even unfavorable reaction pathway. Further, as the loss of aryl radical fragments demonstrates, radical pathways also cannot be excluded. In fact, we have observed the HF-elimination in meso-heptafluoropropyl-substituted porphyrins under ESI conditions that is, under ESI(+) conditions, intermingled with a radical fragmentation pathway of the meso-alkyl groups [35].

The fact that two competing fragmentation pathways ( $\mathrm{HF}$ and $\mathrm{C}_{6} \mathrm{~F}_{5} \cdot$ losses) are observed allows further insight into the regioselectivity of the sequential HF losses. In the MS/MS/MS spectra of the species that 


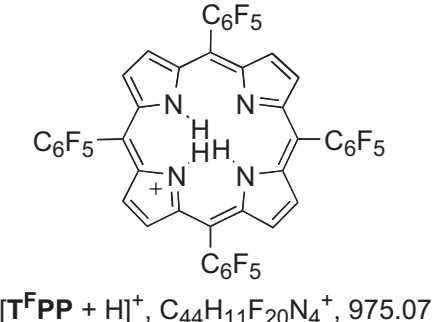

$\left[\mathrm{T}^{\mathrm{F} P P}+\mathrm{H}^{+}, \mathrm{C}_{44} \mathrm{H}_{11} \mathrm{~F}_{20} \mathrm{~N}_{4}{ }^{+}, 975.07\right.$

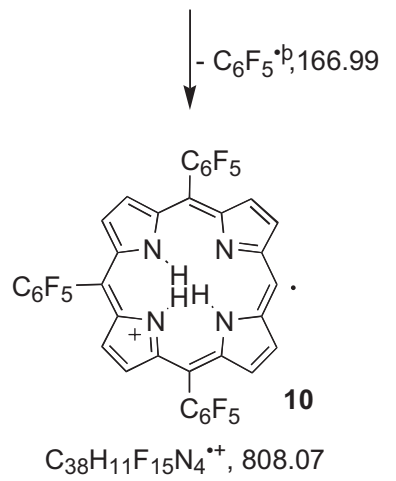

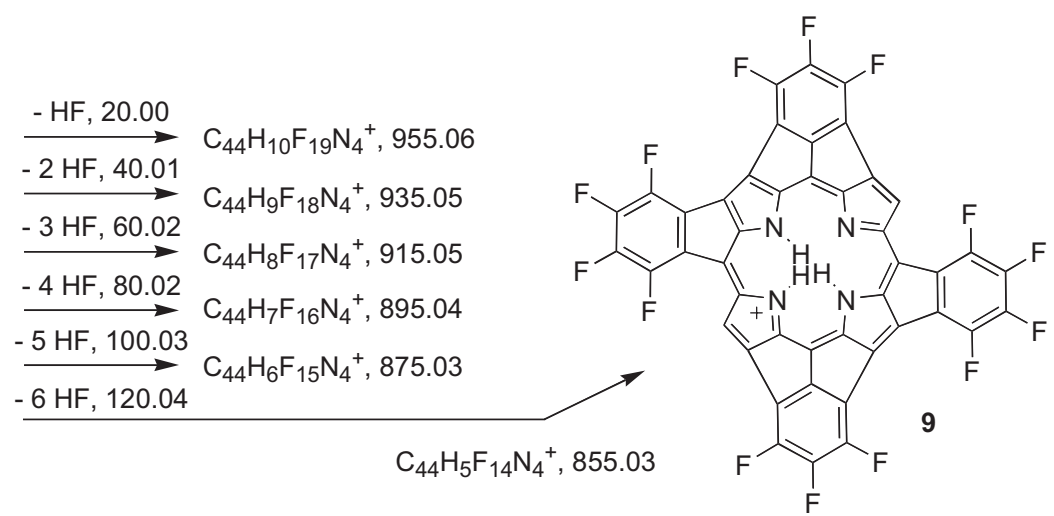

$\stackrel{-\mathrm{HF}, 20.00}{\longrightarrow} \mathrm{C}_{38} \mathrm{H}_{10} \mathrm{~F}_{14} \mathrm{~N}_{4}{ }^{++}, 788.07$
$\stackrel{-2 \mathrm{HF}, 40.01}{\longrightarrow} \mathrm{C}_{38} \mathrm{H}_{9} \mathrm{~F}_{13} \mathrm{~N}_{4}{ }^{\cdot+}, 768.06$
$\stackrel{-3 \mathrm{HF}, 60.02}{\stackrel{-4 \mathrm{HF}, 80.02}{\longrightarrow}} \mathrm{C}_{38} \mathrm{H}_{7} \mathrm{~F}_{11} \mathrm{~N}_{4}{ }^{++}, 728.05$

$\mathrm{C}_{38} \mathrm{H}_{8} \mathrm{~F}_{12} \mathrm{~N}_{4}{ }^{\cdot+}, 748.06$

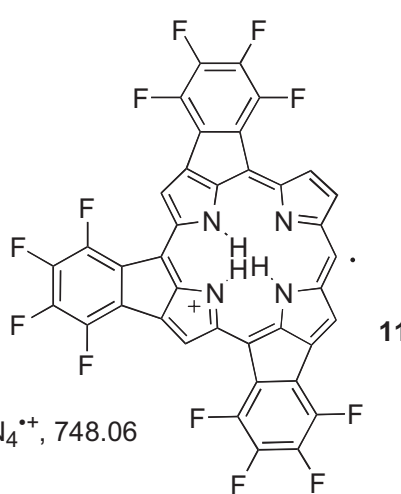

11

Scheme 3. Interpretation of the collision-induced fragmentation mass spectrum of $\left[\mathbf{T}^{\mathrm{F}} \mathbf{P P}+\mathrm{H}\right]^{+}$ (Figure $4 \mathrm{~b}$ ). For clarity, the interpretation of Figures 4C and 4D were omitted.

have lost one to three $\mathrm{HF}$ fragments, the loss of a $\mathrm{C}_{6} \mathrm{~F}_{5}$ fragment is observed in addition to further HF-losses. Representative for this case, Figure 4c shows the MS/ MS/MS spectrum of the $m / z 955$ species ([T ${ }^{\mathrm{F}} \mathbf{P P}+\mathrm{H}-$ $\left.\mathrm{HF}^{+}\right)$. The spectrum looks like the spectrum for $\left[\mathrm{T}^{\mathrm{F}} \mathbf{P P}\right.$ $+\mathrm{H}]^{+}$truncated by the first HF loss. Inversely, only one or two HF losses are observed in the product ions that have already lost three or four HF molecules, respectively. Figure $4 \mathrm{~d}$, the MS/MS/MS spectrum of the $\mathrm{m} / \mathrm{z}$ 915 species $\left(\left[\mathbf{T}^{\mathrm{F}} \mathbf{P P}+\mathrm{H}-3 \mathrm{HF}\right]^{+}\right)$, shows such a case. Only two further HF-losses are observed while there are no indications for any loss of an aryl group. The first fusion makes the loss of an aryl group through a simple meso-ipso single bond breakage impossible. Hence, this finding further supports further the supposition that firstly HF fragmentations occur that fuse all the phenyl groups with a single bond to the macrocycle before a second fusion is established.

\section{ESI(-) MS/MS. Spectra of the $\mathrm{m} / \mathrm{z} 796$ Species Assigned to $\mathrm{T}^{\mathrm{F}} \mathrm{PC}$}

The porphyrin $\mathbf{T}^{\mathrm{F}} \mathbf{P P}$ is made by acid-catalyzed condensation of pyrrole and pentafluorobenzaldehyde. It is well known that this reaction also generates the corresponding corrole $\mathbf{T}^{\mathrm{F}} \mathbf{P C}[44,45]$. Inspection of the mass spectrum of a commercial sample of $\mathbf{T}^{\mathrm{F}} \mathbf{P P}$ clearly shows the presence of this impurity (see Figure 4e).
The collision-induced fragmentation spectra of the precursor ion of the trifluorophenylcorrole $\mathbf{T}^{\mathrm{F}} \mathbf{P C}$ in the ESI $(+)$ and ESI(-) modes are shown in Figure 7a and b, respectively. The ESI(+) spectrum allows for the observation of five HF eliminations, leading to the formation of species 12 and the loss of one pentafluorophenyl group from the precursor ion $(\mathrm{m} / \mathrm{z}$ 797) (Scheme 4). Again, the ESI(-) spectrum provides the clearest spectrum. Three consecutive HF eliminations are visible, presumably one for each pentafluorophenyl group of $\mathbf{T}^{\mathrm{F}} \mathbf{P C}$, forming species 13. This compares to the four high abundance eliminations corresponding to the four fluorophenyl groups in $\mathbf{T}^{\mathrm{F}} \mathbf{P P}$ and the three eliminations for the three fluorophenyl groups in the porphyrin radical species $\mathbf{1 0}$ (Scheme $\mathbf{3}$ ). Hence, the number of HF eliminations observable in the ESI(-) spectra is diagnostic for the number of pentafluorophenyl groups attached to the porphyrinic framework. Similarly important, this observation lends further credence to the validity of the interpretation of the mass spectra.

\section{Conclusions}

We have shown the detailed mass spectrometric analysis of meso-phenyl- and pentafluorophenylsubstituted porphyrins and corroles using positive and negative mode ESI tandem mass spectrometry. The typical and known fragmentation of the phenyl- 

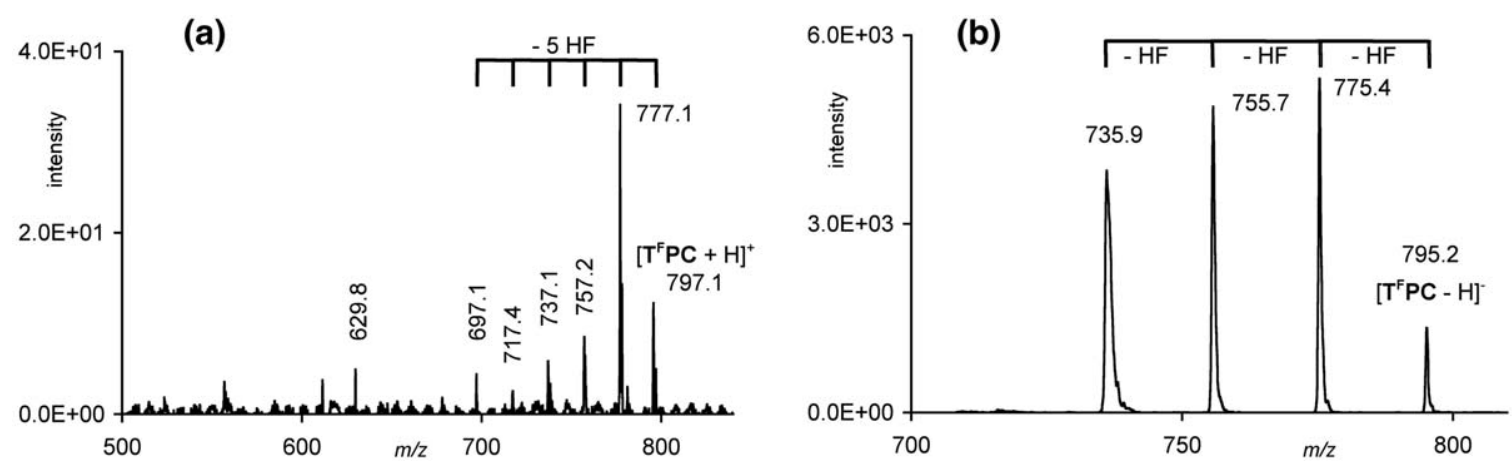

Figure 7. ESI spectra of $\mathbf{T}^{\mathrm{F}} \mathbf{P C}$. (a): ESI(+) MS/MS spectrum of the $m / z 797$ species that is detectable in the full scan spectrum of $\mathbf{T}^{\mathrm{F}} \mathbf{P P}$ and that is assigned to $\left[\mathrm{T}^{\mathrm{F}} \mathbf{P C}+\mathrm{H}\right]^{+}$. (b): ESI $(-) \mathrm{MS} / \mathrm{MS}$ spectrum of the $m / z 795$ species visible in the full scan spectrum of $\mathbf{T}^{\mathrm{T}} \mathbf{P P}$ (Figure $4 \mathrm{e}$ ) and that is assigned to [ $\mathbf{T}^{\mathrm{F}} \mathbf{P C}$

$-\mathrm{H}]^{-}$. An interpretation of the spectra is provided in Scheme 4 .

substituted macrocycles in the positive mode is the loss of phenyl side chains. meso-Pentafluorophenylsubstitution also allows for the recording of spectra in the negative mode whereby this derivatization also changes the MS behavior of porphyrinic macrocycles in a fundamental way in both ionization modes when compared to their meso-phenyl-substituted counterparts. As the predominant fragmentation pattern we have identified the successive loss of HF. We attribute this to the formation of fragment ions with direct $o$-phenyl-to- $\beta$-linkages. This observation, taken together with the observations reported before [33] establishes this fragmentation pathway as likely to be general for meso-pentafluorophenyl-substituted porphyrinoids. The results will facilitate the interpretation of MS spectra of meso-pentafluorophenylsubstituted porphyrinic compounds using ESI mass spectrometry. Whether the observed fragmentation modes can also be adopted for the solution phase bulk synthesis of porphyrins containing coplanarized meso-aryl groups by chemically induced HF eliminations is currently a subject of investigations in our laboratories.

\section{Acknowledgments}

This work was supported by the Department of Defense Multidisciplinary University Research Initiative (MURI) Center on Polymeric Smart Skin Materials through the Air Force Office of Scientific Research contract no. F49620-01-1-0364 (to GEK) and through NSF grant no. 0517782 (to CB). The EsquireLC mass spectrometer was purchased with support by National Science Foundation under grant no. 9807748. The authors thank Marvin Thompson (University of Connecticut) for assistance with the ESI mass spectrometer.

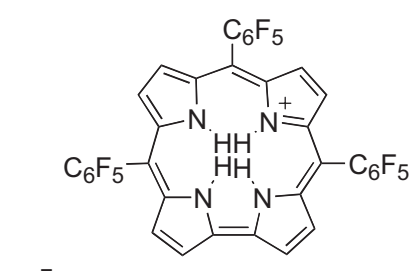

$\left[T^{\mathrm{F} P C}+\mathrm{H}^{+}, \mathrm{C}_{37} \mathrm{H}_{12} \mathrm{~F}_{15} \mathrm{~N}_{4}{ }^{+}, 797.08\right.$<smiles></smiles>

$\mathrm{C}_{31} \mathrm{H}_{11} \mathrm{~F}_{10} \mathrm{~N}_{4}{ }^{-+}, 629.08$

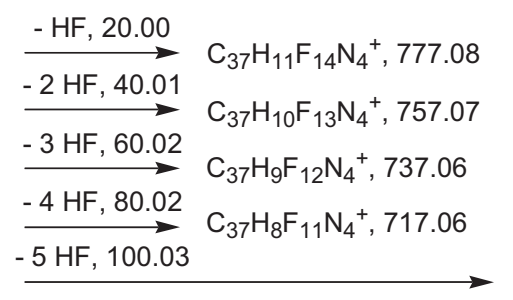

$\mathrm{C}_{37} \mathrm{H}_{7} \mathrm{~F}_{10} \mathrm{~N}_{4}{ }^{+}, 697.05$

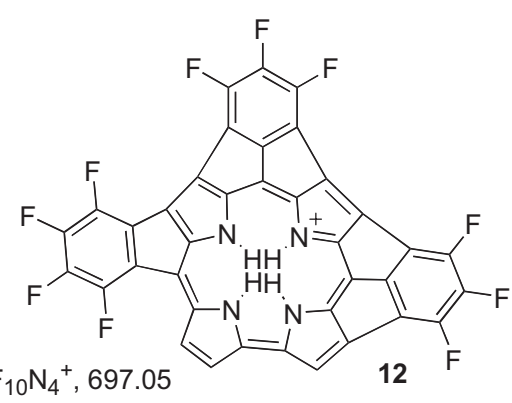

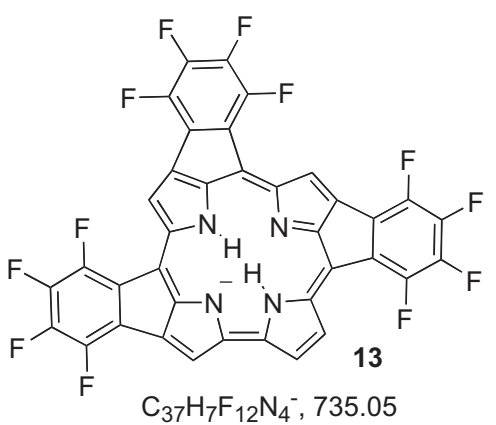

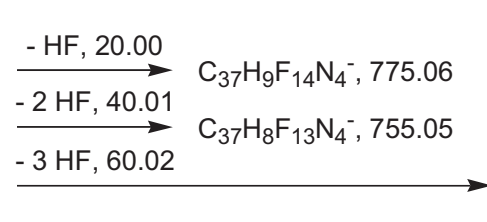

$\mathrm{C}_{37} \mathrm{H}_{8} \mathrm{~F}_{13} \mathrm{~N}_{4}^{-}, 755.05$

[TFPC - H] $]^{-}, \mathrm{C}_{37} \mathrm{H}_{10} \mathrm{~F}_{15} \mathrm{~N}_{4}^{-}, 795.07$

Scheme 4. Interpretation of the collision-induced fragmentation mass spectrum of $\left[\mathbf{T}^{\mathrm{F}} \mathbf{P C}+\mathrm{H}\right]^{+}$. 


\section{References}

1. Lindsey, J. S. In The Porphyrin Handbook Vol. I; Kadish, K. M.; Smith, K. M.; Guilard, R., Eds.; Academic Press: San Diego, 2000, pp 45-118.

2. Mahammed, A.; Goldberg, I.; Gross, Z. Highly Selective Chlorosulfonation of Tris(Pentafluorophenyl)Corrole as a Synthetic Tool for the Preparation of Amphiphilic Corroles and Metal Complexes of Planar Chirality. Org. Lett. 2001, 3, 3443-3446.

3. Silva, A. M. G.; Tome, A. C.; Neves, M. G. P. M. S.; Silva, A. M. S.; Cavaleiro, J. A. S. meso-Tetraarylporphyrins as Dipolarophiles in 1,3Dipolar Cycloaddition Reactions. Chem. Commun. 1999, 1767-1768.

4. Fujii, H. Electronic Structure and Reactivity of High-Valent Oxo Iron Porphyrins. Coord. Chem. Rev, 2002, 226, 51-60.

5. Simkhovich, L.; Galili, N.; Saltsman, I.; Goldberg, I.; Gross, Z. Coordination Chemistry of the Novel 5,10,15-Tris(Pentafluorophenyl)Corrole: Synthesis, Spectroscopy, and Structural Characterization of Its Cobalt(III), Rhodium(III), and Iron(IV) Complexes. Inorg. Chem. 2000, 39, 2704-2705

6. Paul-Roth, C.; Montigny, F. D.; Rethoré, G.; Simonneaux, G.; Gulea, M.; Masson, S. Cyclopropanation of Alkenes with Diisopropyl Diazomethylphosphonate Catalyzed by Ruthenium Porphyrin Complexes. J. Mol. Catal. A 2003, 201, 79-91.

7. Rosenthal, J.; Pistorio, B. J.; Chng, L. L.; Nocera, D. G. Aerobic Catalytic Photooxidation of Olefins by an Electron-Deficient Pacman Bisiron(III)Oxo Porphyrin. J. Org. Chem. 2005, 70, 1885-1888.

8. Furuta, H.; Maeda, H.; Osuka, A. Doubly N-Confused Porphyrin: A New Complexing Agent Capable of Stabilizing Higher Oxidation States. I. Am. Chem. Soc. 2000, 122, 803-807.

9. Maeda, H.; Osuka, A.; Ishikawa, Y.; Aritome, I.; Hisaeda, Y.; Furuta, H. $\mathrm{N}$-Confused Porphyrin-Bearing meso-Perfluorophenyl Groups: A Potential Agent That Forms Stable Square-Planar Complexes with $\mathrm{Cu}(\mathrm{II})$ and Ag(III). Org. Lett. 2003, 5, 1293-1296.

10. Shin, J.-Y.; Furuta, H.; Osuka, A. N-Fused Pentaphyrin. Angew. Chem. Int. Ed. 2001, 40, 619-621.

11. Sternberg, E. D.; Dolphin, D.; Brückner, C. Porphyrin-Based Photosensitizers for Use in Photodynamic Therapy. Tetrahedron 1998, 54, 41514202 .

12. Gouterman, M. Oxygen Quenching of Luminescence of Pressure Sensitive Paint for Wind Tunnel Research. I. Chem. Ed. 1997, 74, 697-702.

13. Zelelow, B.; Khalil, G. E.; Phelan, G.; Carlson, B.; Gouterman, M.; Callis, J. B.; Dalton, L. R. Dual Luminophor Pressure Sensitive Paint. II. Lifetime Based Measurement of Pressure and Temperature. Sens. Actuators B 2003, 96, 304-314.

14. Khalil, G.; Gouterman, M.; Ching, S.; Costin, C.; Coyle, L.; Gouin, S.; Green, E.; Sadilek, M.; Wan, R.; Yearyean, J.; Zelelow, B. Synthesis and Spectroscopic Characterization of Ni, Zn, Pd, and Pt Tetra(Pentafluorophenyl)Porpholactone with Comparison to $\mathrm{Mg}, \mathrm{Zn}, \mathrm{Y}, \mathrm{Pd}$, and Pt. Metal Complexes of Tetra(Pentafluorophenyl)Porphine. J. Porphyrins Phthalocyanines 2002, 6, 135-145.

15. Khalil, G. E.; Costin, C.; Crafton, J.; Jones, G.; Grenoble, S.; Gouterman, M.; Callis, J. B.; Dalton, L. R. Dual-Luminophor Pressure-Sensitive Paint. I. Ratio of Reference to Sensor Giving a Small Temperature Dependency. Sens. Actuators B 2004, 97, 13-21.

16. Gouterman, M.; Callis, J.; Dalton, L.; Khalil, G.; Mebarki, Y.; Cooper, K. R.; Grenier, M. Dual Luminophor Pressure-Sensitive Paint: III. Application to Automotive Model Testing. Meas. Sci. Technol. 2004, 15, 1986-1994.

17. Ayorinde, F. O.; Hambright, P.; Porter, T. N.; Q. L. Keith, J. Use of meso-Tetrakis(Pentafluorophenyl)Porphyrin as a Matrix for Low Molecular Weight Alkylphenol Ethoxylates in Laser Desorption/Ionization Time-of-Flight Mass Spectrometry. Rapid Commun. Mass Spectrom. 1999, $13,2474-2479$.

18. Shaw, S. J.; Elgie, K. J.; Edwards, C.; Boyle, R. W. Mono-(Pentafluorophenyl)Porphyrins-Useful Intermediates in the Regioselective Synthesis of Multifunctionalized Porphyrins. Tetrahedron Lett. 1999, 40, 15951596.

19. Elgie, K. J.; Scobie, M.; Boyle, R. W. Application of Combinatorial Techniques in the Synthesis of Unsymmetrically Substituted 5,15Diphenylporphyrins. Tetrahedron Lett. 2000, 41, 2753-2757.

20. Pasetto, P.; Chen, X.; Drain, C. M.; Franck, R. W. Synthesis of Hydrolytically Stable Porphyrin C- and S-Glycoconjugates in High Yields. Chem. Commun. 2001, 81-82.

21. Chen, X.; Hui, L.; Foster, D. A.; Drain, C. M. Efficient Synthesis and Photodynamic Activity of Porphyrin-Saccharide Conjugates: Targeting and Incapacitating Cancer Cells. Biochemistry 2004, 43, 10918-10929.
22. DiMagno, S. G.; Dussault, P. H.; Schultz, J. A. Fluorous Biphasic Singlet Oxygenation with a Perfluoroalkylated Photosensitizer. J. Am. Chem. Soc. 1996, 118, 5312-5313

23. Birnbaum, E. R. Le Lacheur, R. M. Horton, A. C. Tumas, W. Metalloporphyrin-Catalyzed Homogeneous Oxidation in Supercritical Carbon Dioxide. J. Mol. Catal. A 1999, 139, 11-24.

24. Birnbaum, E. R.; Schaefer, W. P.; Labinger, J. A.; Bercaw, J. E.; Gray, H. B. Electronic Structures of Halogenated Ruthenium Porphyrins. Crystal Structure of $\mathrm{RuTFPPCl}_{8}(\mathrm{co}) \mathrm{H}_{2} \mathrm{O}$ (TFPPCl $\mathrm{TP}_{8}=$ Octa- $\beta$-Chlorotetrakis(Pentafluorophenyl)Porphyrin). Inorg. Chem. 1995, 34, 1751-1755.

25. Van Berkel, G. J.; McLuckey, S. A.; Glish, G. L. Electrospray Ionization of Porphyrins Using a Quadrupole Ion Trap for Mass Analysis. Anal. Chem. 1991, 63, 1098-1109.

26. Vandell, V. E.; Limbach, P. A. Electrospray Ionization Mass Spectrometry of Metalloporphyrins. J. Mass Spectrom. 1998, 33, 212-220.

27. Berkel, G. J. V.; Quinones, M. A.; Quirke, J. M. E. Geoporphyrin Analysis Using Electrospray Ionization-Mass Spectrometry. Energy Fuels 1993, 7, 411-419.

28. Airs, R. L.; Keely, B. J. A Novel Approach for Sensitivity Enhancement in Atmospheric Pressure Chemical Ionization Liquid Chromatography/ Mass Spectrometry of Chlorophylls. Rapid Commun. Mass Spectrom. 2000, 14, 125-128.

29. Quirke, J. M. E. In The Porphyrin Handbook Vol.VII; Kadish, K. M.; Smith, K. M.; Guilard, R., Eds.; Academic Press: San Diego, 2000; pp 371-426.

30. Domingues, M. R. M.; S.-Marques, M. G. O. S.; Alonso, C. M. A.; Neves, M. G. P. M. S.; Cavaleiro, J. A. S.; Ferrer-Correia, A. J.; Nemirovskiy, O. V.; Gross, M. L. Unexpected Fragmentation of $\beta$-Substituted mesoTetraphenylporphyrins Induced by High-Energy Collisional Activation. J. Am. Soc. Mass Spectrom. 2002, 13, 1427-1431.

31. McCarthy, J. R.; Melfi, P. J.; Capetta, S. H.; Brückner, C. Use of Ag(II) as a Removable Template in Porphyrin Chemistry: Diol Cleavage Products of [meso-Tetraphenyl-2,3-cis-Diolchlorinato]Silver(II). Tetrahedron 2003, 59, 9137-9146.

32. Domingues, M. R. M.; Domingues, P.; Reis, A.; Ferrer-Correira, A. J.; Tomé, J. P. C.; Tomé, A. C.; Neves, M. G. P. M. S.; Cavaleiro, J. A. S. Structural Characterization of Glycoporphyrins by Electrospray Tandem Mass Spectrometry. J. Mass Spectrom. 2004, 39, 158-167.

33. Izquerido, R. A.; Barros, C. M.; Santana-Marques, M. G.; Correia, A. J. F.; Silva, A. M. G.; Tomé, A. C.; Silva, A.; Neves, M. G. P. M. S.; Cavaleiro, J. A. S. Cycloreversion and Other Gas-Phase Reactions of Neutral and Cationic Pyrrolidine-Fused Chlorins and Isobacteriochlorins under Ion Bombardment and Electrospray. Rapid Commun. Mass Spectrom. 2004, 18, 2601-2611.

34. Silva, E. M. P. Domingues, M. R. M. Barros, C. Faustino, M. A. F. Tomé, J. P. C.; Neves, M. G. P. M. S.; Tomé, A. C.; Santana-Marques, M. G.; Cavaleiro, J. A. S.; Ferrer-Correia, A. J. Characterization of Dinitroporphyrin Zinc Complexes by Electrospray Ionization Tandem Mass Spectrometry. Unusual Fragmentations of $\beta$-(1,3-Dinitroalkyl) Porphyrins. J. Mass Spectrom. 2005, 40, 117-122.

35. Lau, K. S. F.; Sadilek, M.; Khalil, G. E.; Gouterman, M.; Brückner, C. Tandem ESI Mass Spectrometric Analysis of meso-tetrakis(Heptafluoropropyl)-Porphyrin. J. Am. Soc. Mass Spectrom. 2005, 16, 1915-1920.

36. Domingues, M. R. M. S.-Marques, M. G. O.; Domingues, P. Graca Neves, M.; Cavaleiro, J. A. S.; Ferrer-Correia, A. J. Differentiation of Positional Isomers of Nitro meso-Tetraphenylporphyrins by Tandem Mass Spectrometry. Am. Soc. Mass Spectrom. 2001, 12, 381-384.

37. Adler, A. D.: Longo, F. R.; Finarelli, J. D.; Goldmacher, J.; Assour, J.; Korsakoff, L. A Simplified Synthesis for TPP. J. Org. Chem. 1967, 32, 476.

38. Briñas, R. P.; Brückner, C. Triarylcorroles by Oxidative Coupling of Triaryltetrapyrranes. Synlett. 2001, 442-444.

39. Mahammed, A.; Weaver, J. J.; Gray, H. B.; Abdelas, M.; Gross, Z. How Acidic are Corroles and Why? Tetrahedron Lett. 2003, 44, 2077-2079.

40. Barloy, L.; Dolphin, D.; Dupré, D.; Wijesekera, T. P. J. Anomalous Double Cyclization Reactions of $\beta$-Formylporphyrins. J. Org. Chem. 1994, 59, 7976-7985.

41. Aihara, H.; Jaquinod, L.; Nurco, D. J.; Smith, K. M. Multicarbocycle Formation Mediated by Arenoporphyrin 1,4-Diradicals: Synthesis of Picenoporphyrins. Angew. Chem. Int. Ed. 2001, 40, 3439-3441.

42. Daniell, H. W.; Brückner, C. Enantiomeric Resolution of a Ruffled Porphyrinoid. Angew. Chem. Int. Ed. 2004, 43, 1688-1691.

43. Fox, S.; Boyle, R. W. First Examples of Intramolecular Pd(0) Catalyzed Couplings on Ortho-Iodinated meso-Phenyl Porphyrins. Chem. Commun. 2004, 1322-1323.

44. Gross, Z.; Galili, N.; Saltsman, I. The First Direct Synthesis of Corroles from Pyrrole. Angew. Chem. Int. Ed. 1999, 38, 1427-1429.

45. Paolesse, R.; Mini, S.; Sagone, F.; Boschi, T.; Jaquinod, L.; Nurco, D. J.; Smith, K. M. 5,10,15-Triphenylcorrole: A Product from a Modified Rothemund Reaction. Chem. Commun. 1999, 1307-1308. 